\title{
COMPORTAMENTO AERODINÂMICO E EFEITO DE ENRIJECIMENTO EXTERNO EM SILOS CILÍNDRICOS SOB A AÇÃO DO VENTO
}

\author{
LUCIANO J. DE ANDRADE JÚNIOR ${ }^{1}$, CARLITO CALIL JÚNIOR ${ }^{2}$
}

RESUMO: Os silos metálicos, quando vazios, são suscetíveis ao amassamento das chapas do corpo cilíndrico pela ação do vento. Este trabalho compara os efeitos do enrijecimento interno e externo com colunas, no comportamento aerodinâmico de silos cilíndricos com telhado cônico. Os estudos teóricos conduziram a ensaios em túnel de vento, que foram realizados em dois tipos de modelos reduzidos: um com superfície lisa (enrijecimento interno) e o outro com superfície nervurada (enrijecimento externo), ambos em duas relações geométricas de altura/diâmetro do cilindro $(0,5$ e 1,0$)$ e inclinação da cobertura cônica de $27^{\circ}$. Com base nos ensaios, foram obtidos os coeficientes de pressão externa e os coeficientes de arrasto nos cilindros, bem como os coeficientes de arrasto e de sustentação na cobertura. Com isso, identificou-se o melhor tipo de enrijecimento ao projeto otimizado de silos para resistir adequadamente à ação do vento. $\mathrm{O}$ resultado final é um conjunto de dados atualizado, oriundo de ensaios com características de semelhança geométrica e aerodinâmica definidas, que é aplicável a qualquer tipo de silo cilíndrico.

PALAVRAS-CHAVE: coeficientes aerodinâmicos, silos cilíndricos, enrijecimento externo.

\section{AERODYNAMIC BEHAVIOUR AND EXTERNAL STIFFENING EFFECT IN CYLINDRICAL SILOS UNDER WIND ACTION}

SUMMARY: Steel cylindrical silos, when empty, are susceptible to the crumpling of the sheeting of the cylinder by the wind action. This paper compares the effects of internal and external stiffening with columns on the aerodynamic behavior of cylindrical silos with conical roof. The theoretical studies leaded to wind tunnel experiments, which have been carried out on two types of scaled silo models, one with smooth surface (internal stiffening), the other with ribbed surface (external stiffening), both with two geometric height/diameter ratio of cylinder (0.5 and 1.0) and a conical roof pitch equal to $27^{\circ}$. Based on the information gained during these experiments, external coefficients of pressure and drag and lift coefficients are derived for the cylinders, as well as the drag and lift coefficients for the conical roofs. With this, it is identified the best stiffening arrangement for an optimum design of cylindrical silos to resist wind loads. The final result is an updated data set, originated from tests with geometric and aerodynamic characteristics well conditioned, which are applicable to a variety of cylindrical silos.

KEYWORDS: aerodynamic coefficients, cylindrical silos, external stiffening.

\footnotetext{
${ }^{1}$ Engenheiro Civil, Doutor em Engenharia Civil, Kepler Weber Industrial S.A., Av. Adolfo Kepler Junior 1500, Panambi - RS, Fone: (0XX55) 3375.9987, Fax: (0XX55) 3375.9881, e-mail: jorgeandrade@kepler.com.br

2 Prof. Titular, Escola de Engenharia de São Carlos, EESC/USP, Fone/Fax: (0XX16) 273.9483, e-mail: calil@ sc.usp.br

Recebido pelo Conselho Editorial em: 30-5-2003

Aprovado pelo Conselho Editorial em: 26-8-2004 


\section{INTRODUÇÃO}

A operação de um silo abrange o ciclo de armazenagem, desde o carregamento até a descarga, quando pode permanecer parcialmente ou totalmente vazio por um dado período. Nesse caso, o silo cilíndrico metálico é especialmente suscetível à ação do vento, em conseqüência da grande eficiência estrutural da forma cilíndrica, da resistência elevada dos aços empregados e da grande relação entre o volume de armazenagem e o peso da estrutura. Em consequiência desses fatores e da predominância do dimensionamento do silo na condição de armazenagem e operações de carga e de descarga, por exemplo, as relações entre a espessura da chapa de aço e o diâmetro do cilindro do silo variam de 10.000 a 14.000 .

Em silos grandes, essa suscetibilidade se mostra na forma de amassamento do corpo cilíndrico, ou costado, como demonstrado por ANDRADE JÚNIOR (2002). Esse fenômeno ocorre na região de incidência do vento, logo abaixo do telhado, conforme Figura 1.
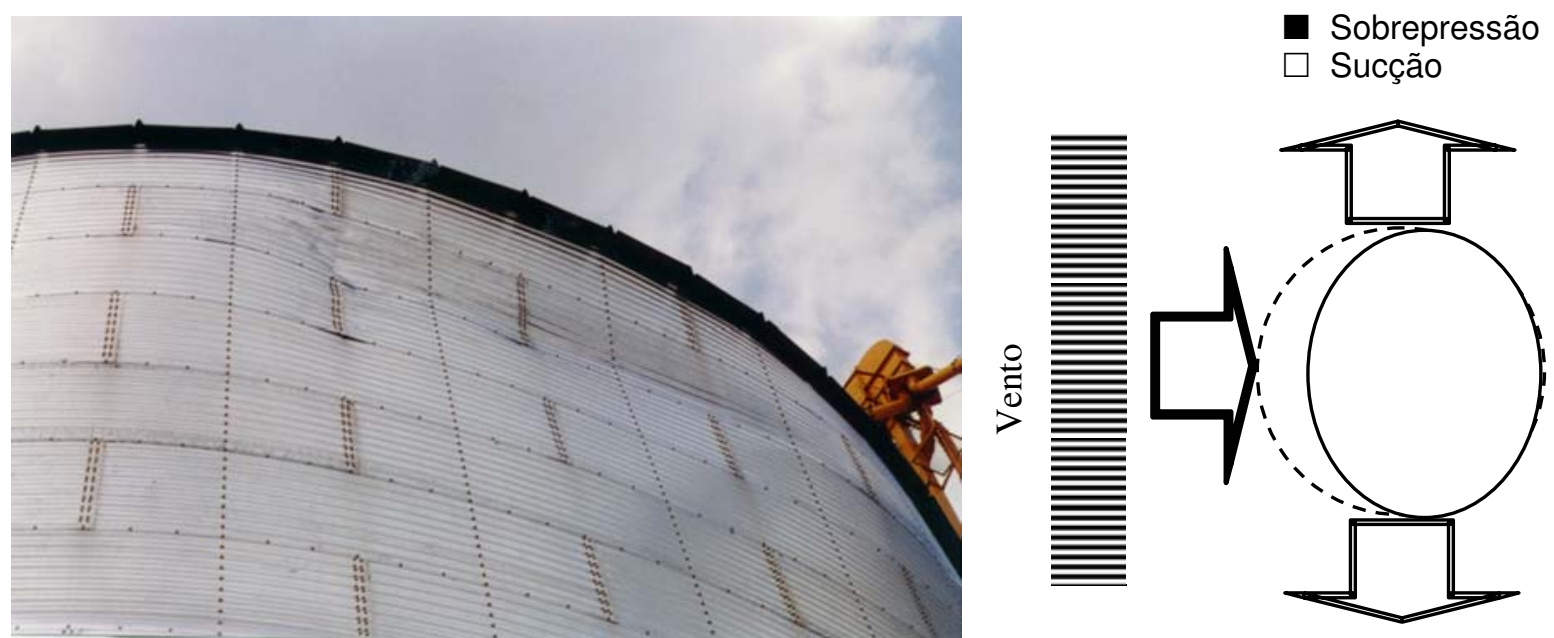

FIGURA 1. Silo cilíndrico metálico amassado pela força do vento (2001) e o efeito de ovalização.

Para avaliar a condição aerodinâmica do silo cilíndrico e também a suscetibilidade de falha do silo metálico, é necessário compreender a ação do vento, a estrutura do silo e a interação do vento com o silo, de acordo com ANDRADE JÚNIOR \& CALIL JÚNIOR (1999). Vale salientar que o presente estudo abrange todos os silos cilíndricos para a avaliação aerodinâmica, independentemente do material que seja feita a estrutura, e avalia, particularmente no silo metálico, a suscetibilidade de amassamento do costado.

As características dos ventos dependem das condições topográficas, meteorológicas e da distribuição de edificações e de obstáculos naturais na vizinhança do silo. O silo é classificado pela relação altura/diâmetro do corpo: curto $(\mathrm{H} / \mathrm{D} \leq 0,5)$, médio ou intermediário $(0,5<\mathrm{H} / \mathrm{D} \leq 1,0)$ e longo $(\mathrm{H} / \mathrm{D}>1,5)$.

A estrutura do silo é composta por corpo cilíndrico e cobertura cônica, interligados entre si. O cilindro, ou costado, suporta principalmente os esforços solicitantes do produto armazenado e, secundariamente, os esforços oriundos de intempéries, sendo, no caso do silo metálico, composto por chapas unidas por parafusos e colunas ou montantes parafusados às chapas. A cobertura cônica suporta os esforços do próprio peso, dos acessórios (por exemplo, respiros, mecanismos espalhadores de grãos, cabos para a medição de temperatura na massa armazenada) e das intempéries, sendo composta por telhas e estrutura reticulada (e.g., conjunto de chapas, longarinas e travessas nos silos metálicos). 
$\mathrm{Na}$ aerodinâmica do silo cilíndrico, classificado como um corpo rombudo, a resistência devido à forma é muito maior que a de atrito do ar com a superfície do corpo, que raramente ultrapassa $1 \%$ da resistência total (BLESSMANN, 1983). O escoamento principal do ar é bloqueado pela esteira turbulenta de vórtices o qual se forma a sotavento. Com o estudo aerodinâmico, é possível determinar as pressões sobre a superfície do silo e as forças resultantes de arrasto para o costado e de arrasto e de sustentação para o telhado. Para o silo cilíndrico metálico, o fenômeno de interação do vento com o silo em si é complexo devido à distribuição espacial do vento e ao sistema da estrutura do silo. Além disso, há uma interação entre o enrijecimento externo (colunas ou montantes) e o vento que interfere no comportamento aerodinâmico e tem efeitos na resposta da estrutura. Uma abordagem analítica, embora possível, é complexa e dificultada principalmente pela modelagem da interação vento/ estrutura, inclusive a perda de estabilidade. Portanto, a melhor abordagem é o ensaio de modelos reduzidos em túnel de vento, devidamente modelados pela análise dimensional e teoria da semelhança e dos modelos físicos, conforme ANDRADE JÚNIOR et al. (2000).

Os ensaios foram realizados no túnel de vento de camada limite da Universidade de Cranfield, na Inglaterra, com o objetivo de determinar e comparar entre si as distribuições das pressões do vento e os coeficientes aerodinâmicos para os modelos com e sem enrijecimento externo. Com base neste estudo, é fornecido um guia prático para o projeto eficiente de silo à ação do vento, no qual se indica a melhor disposição dos montantes.

\section{MATERIAL E MÉTODOS}

Os métodos utilizados compreendem a análise dimensional e a teoria da semelhança física, e técnicas de ensaios em túnel de vento para medições de velocidade do vento e de pressões na superfície externa dos modelos reduzidos de silos. Na análise dimensional, estão definidas as leis para os modelos físicos reduzidos, que são fundamentadas no princípio de semelhança entre dois processos, quais sejam, a ação do vento sobre silos em escala real (protótipos) e a ação do vento gerado em túnel de vento sobre modelos reduzidos dos silos.

Para os ensaios em túnel de vento, são definidos os parâmetros para a geração do escoamento de ar e as medições da velocidade e da turbulência, com o objetivo de simular a camada limite atmosférica (CLA), no túnel de vento, e as diretrizes para os processos de aquisição, gravação, preparação, qualificação e análise de dados para a determinação das pressões externas sobre os modelos reduzidos dos silos.

As técnicas de ensaios em túnel de vento envolvem a geração do escoamento de ar no túnel e as medições de pressões na superfície externa dos modelos. Na análise dimensional, o objetivo é estabelecer as condições de semelhança física entre o modelo reduzido e o protótipo do silo em escala real. Essas condições seguem o princípio de que as escalas das grandezas existentes no protótipo (subscrito p) e no modelo (subscrito m) tenham relações iguais. Essas relações são indicadas por números chamados $\Pi$ e o fator de escala $\lambda$. Por exemplo, se o modelo é confeccionado 10 vezes menor que o protótipo, então o fator de escala é geométrico e definido $\lambda_{\mathrm{L}}=1 / 10$. A partir do estudo desenvolvido por ANDRADE JÚNIOR et al. (2000), foram determinados os fatores de escala e as condições de semelhança apresentados na Tabela 1.

Nos ensaios em túnel de vento, o objetivo é definir a condição de escoamento do ar e a pressão resultante na superfície do modelo reduzido. O problema de simular a interação entre o escoamento gerado dentro de um túnel de vento e um modelo depende da redução adequada das características do vento natural que atua sobre a estrutura real. Para propósitos da engenharia, é suficiente modelar aquele escoamento às condições, admitidas localmente estacionárias, da CLA (ASCE, 1997). Dentro do túnel, a turbulência é gerada com uma superfície rugosa e gradiente de pressão nulo. Os parâmetros escolhidos para os ensaios foram a velocidade média longitudinal $\boldsymbol{U}$; as flutuações dessa velocidade, 
dada pela intensidade de turbulência $\boldsymbol{I}_{N}$; um tempo característico $\boldsymbol{T}_{\boldsymbol{c}}$, necessário para definir a velocidade de tal modo que os vórtices ou turbilhões, originados dessas flutuações, forneçam rajadas de "dimensões suficientes para envolver completamente o modelo" (BLESSMANN, 1995); e $z_{0}$, medida da rugosidade do terreno e, por isso, é conhecida como comprimento de rugosidade.

TABELA 1. Fatores de escala e condições de semelhança dos modelos

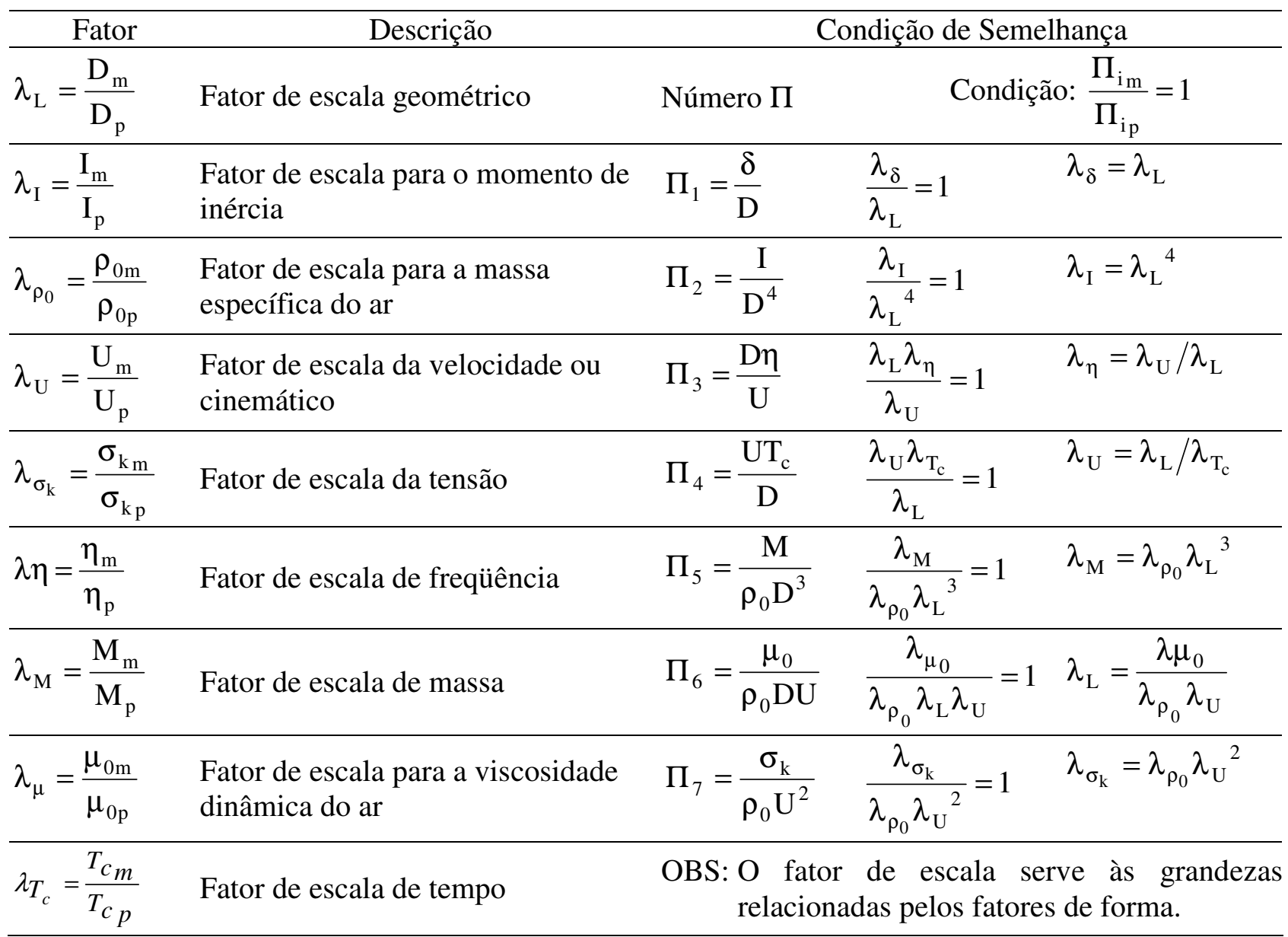

As medidas das velocidades do escoamento de ar foram feitas com anemômetro de fio quente. A técnica empregada para a geração da turbulência advém da necessidade de gerar uma camada limite turbulenta em um túnel de vento relativamente curto. A questão é que, na prática, não é simples fazer um túnel longo o bastante para desenvolver as camadas limites com profundidade suficiente, e o crescimento delas deve ser acelerado artificialmente por meio de dispositivos posicionados no piso do túnel. Os dispositivos simulam uma situação em que são medidas as velocidades do vento e suas flutuações para, a partir desses dados, ser aferido o vento com os perfis normalizados de velocidade média, perfis de intensidade de turbulência local e normalizada, e as escalas temporal e espacial da turbulência. Vale esclarecer que a escala espacial serve para a caracterização da não-uniformidade das rajadas do vento e a escala temporal para o estudo da repetição das rajadas. Os dispositivos de geração de turbulência foram confeccionados em madeira, papelão, plástico e aço, e colocados dentro do túnel, conforme Figura 2.

A função da barreira é prover um déficit inicial de momento, representando o efeito de um campo de rugosidade mais longo. A dos geradores de vórtices (obeliscos) é distribuir esse momento pela camada limite em desenvolvimento e influenciam na turbulência média; a grade é usada para 
gerar turbulência média. Os elementos de rugosidade ao longo do campo representam a superfície rugosa na vizinhança da estrutura real (árvores e cercas), conforme o valor de $\mathrm{z}_{0}$. A altura da barreira é bem determinada pelo aumento de sua altura por incrementos para produzir uma família de camadas limites. As medidas das pressões nos modelos são obtidas da diferença entre uma pressão de referência, que é a pressão estática no escoamento livre, ou pressão estática ao longe, e a pressão estática na superfície do modelo. Essa diferença é chamada pressão efetiva externa, ou simplesmente pressão externa. O processo de medição é feito por meio de válvulas de busca automática das tomadas de pressão situadas na superfície do modelo e pelo anel estático para a tomada de pressão de referência na seção do túnel.
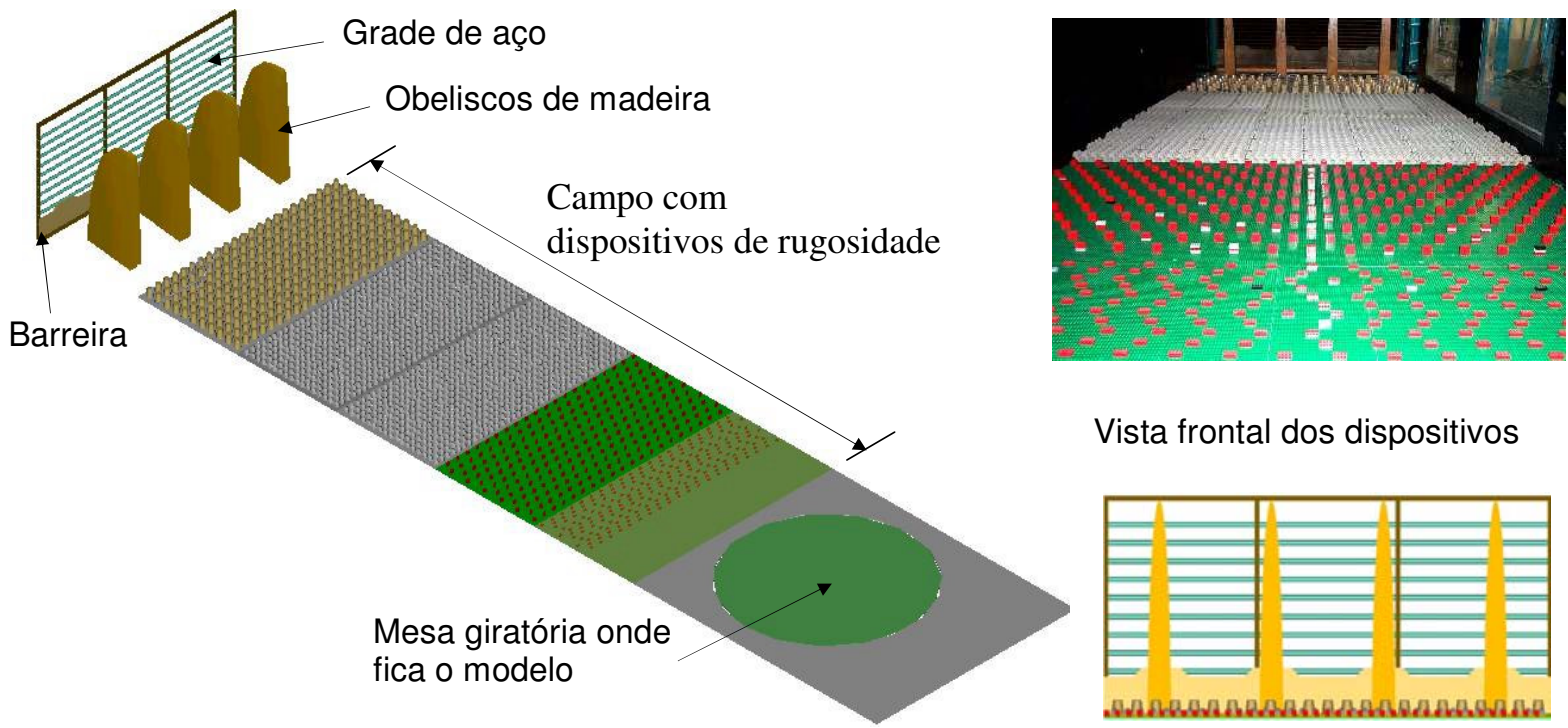

Vista frontal dos dispositivos

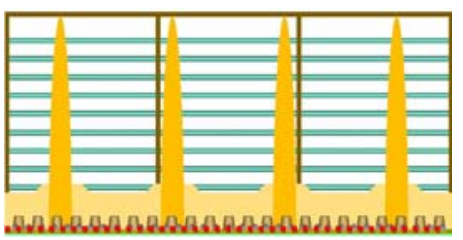

FIGURA 2. Posicionamento dos dispositivos dentro do túnel.

Na Figura 3, apresenta-se no túnel o arranjo do modelo, manômetros, anel estático para a tomada de pressão de referência, dos transdutores de pressão, das válvulas, das conexões das válvulas aos transdutores e deles à placa conversora AC/DC no micro.

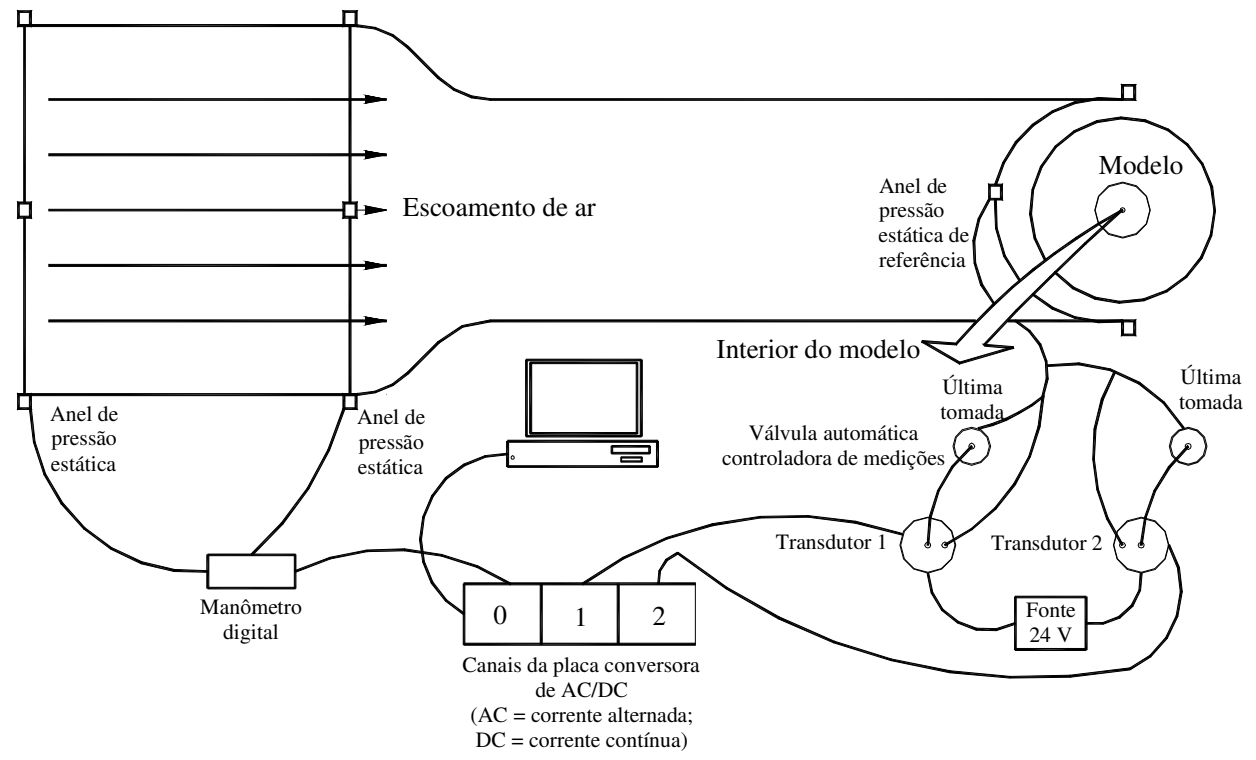

FIGURA 3. Diagrama de aquisição das pressões. 
Os parâmetros para o cálculo dos coeficientes de pressão externa $C_{p e}$ são pressão estática de referência $p_{r e f}$, pressão estática na superfície do modelo $p_{m}$, velocidade média do vento $U$ e densidade do ar $\rho_{0}$. O valor dos coeficientes de pressão é calculado pela eq.(1).

$$
\mathrm{C}_{\mathrm{pe}}=\frac{\mathrm{p}_{\mathrm{m}}-\mathrm{p}_{\mathrm{ref}}}{\frac{1}{2} \rho_{0} \mathrm{U}^{2}}
$$

Os modelos reduzidos foram construídos em duas relações altura/diâmetro (H/D) iguais a 0,5 e 1,0 para o estudo do comportamento aerodinâmico e aeroelástico dos silos. Para tanto, foram definidos dois tipos de modelos, um rígido e outro flexível. Neste trabalho, serão tratados os rígidos, com os quais são obtidos as pressões e os coeficientes aerodinâmicos dos silos com superfície lisa e com superfície nervurada, que representa o enrijecimento externo. $\mathrm{Na}$ Tabela 2, apresentam-se as dimensões dos protótipos e dos modelos, considerando-se a razão $\mathrm{H} / \mathrm{D}$, a altura $\mathrm{b}=0,25 \mathrm{D}$, e a redução geométrica $\lambda_{\mathrm{L}}=1 / 42$. O protótipo de relação $\mathrm{H} / \mathrm{D}=0,5$ tem $11.175 \mathrm{~m}^{3}$ e o de $\mathrm{H} / \mathrm{D}=1,0$ tem $8.456 \mathrm{~m}^{3}$, respectivamente, com capacidades para 8.380 t e $6.342 \mathrm{t}$, para grãos com massa específica de $0,75 \mathrm{t} \mathrm{m}^{-3}$.

TABELA 2. Dimensões dos modelos em função dos diâmetros dos silos protótipos.

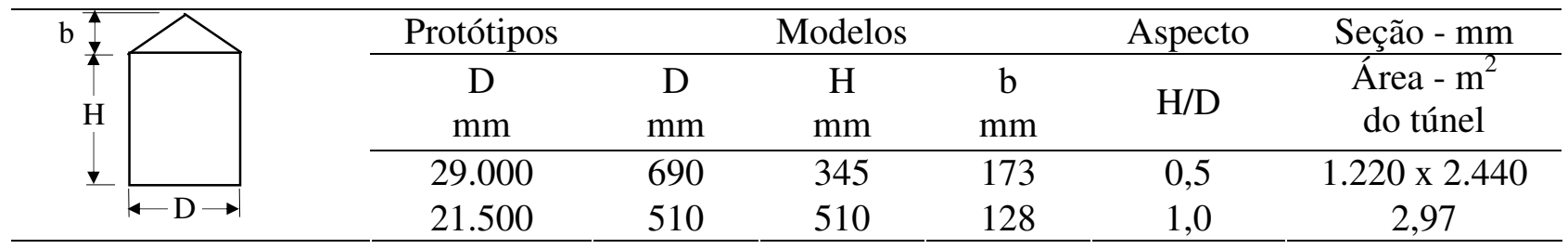

O modelo rígido é feito em lâminas de madeira compensada, com microtubos (1 mm de diâmetro interno) de cobre embutidos nas paredes e usados para tomadas externas de pressão, microtubos em polivinilclorado (PVC) para as conexões entre as tomadas e as válvulas, e entre essas e os transdutores de pressão. Os elementos externos são em madeira e plástico polietilenoterefitalato (PET) para simular as colunas no corpo cilíndrico, e em fios de cobre para simular as dobras radiais das telhas na cobertura cônica. Em cada modelo, há um conjunto de orifícios para as tomadas de pressão contínua e igualmente distribuídos a $10 \mathrm{~mm}$ a partir da base até o topo do cilindro, e do beiral até o ápice da cobertura. No total, são 1.502 tomadas de pressão no modelo 0,5 e 1.388 no modelo 1,0. Na Figura 4, são apresentados os modelos com elementos externos. Os modelos em superfície lisa são os mesmos, mas sem os elementos. As dimensões dos elementos estão na Tabela 3. São 48 colunas no corpo do modelo 0,5 e 36 no corpo do modelo 1,0, sendo as de 4 x $7 \mathrm{~mm}$ na porção inferior. Nas coberturas, são 12 fios grandes e 12 médios em ambos os modelos, e 24 fios curtos adicionalmente à do modelo 0,5. 

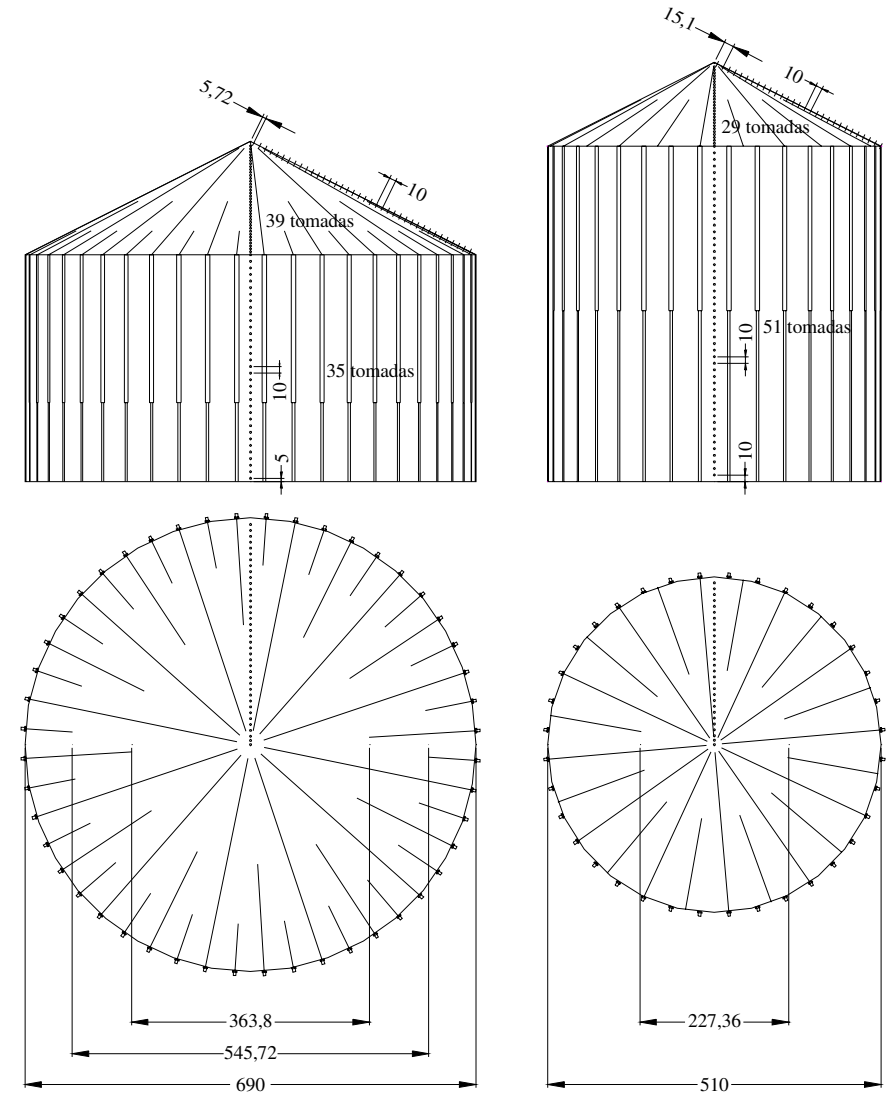
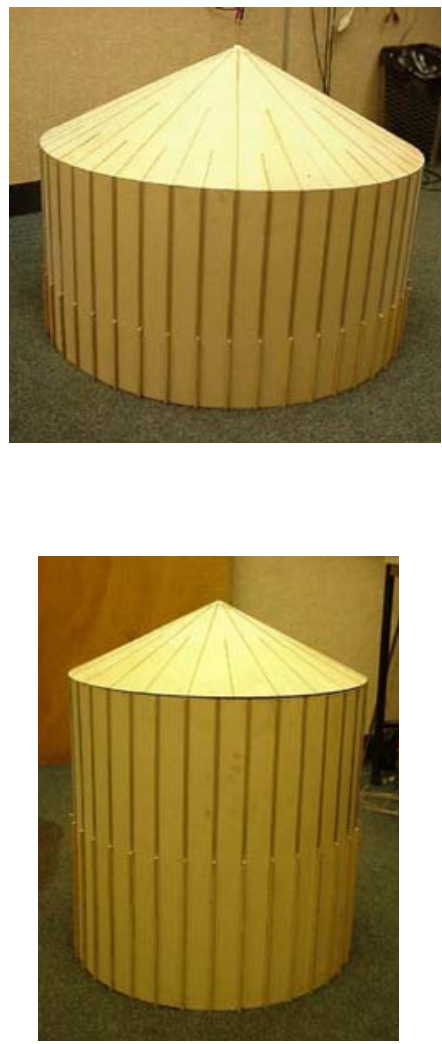

FIGURA 4. Modelos com tomadas de pressão e elementos externos

TABELA 3. Dimensões das colunas e dos fios para os modelos (largura segue circunferência).

\begin{tabular}{ccccc}
\hline & \multicolumn{3}{c}{ Dimensões das Colunas $(\mathrm{mm})$} & \multirow{2}{*}{ Fio, $\phi=1,0 \mathrm{~mm}$} \\
& Comprimento & Largura & Espessura & Comprimento \\
\hline \multirow{2}{*}{ Modelo 0,5 } & 120 & 4 & 7 & 724 \\
& 225 & 7 & 2 & $365 \mathrm{e} \mathrm{161}$ \\
\hline \multirow{2}{*}{ Modelo 1,0 } & 260 & 4 & 7 & 544 \\
& 250 & 7 & 2 & 316 \\
\hline
\end{tabular}

Para atender à metodologia requerida, foram seguidos os procedimentos que garantiram o desenvolvimento adequado dos ensaios, conforme as diretrizes apresentadas na Tabela 4. Para uma visão geral, são apresentadas na Tabela 5 as características dos ensaios dos modelos no túnel de vento. É importante notar que a menção ao modelo flexível é para a composição geral deste estudo, mas os resultados correspondentes serão expostos em um próximo artigo. 
TABELA 4. Diretrizes para o desenvolvimento dos ensaios.

\begin{tabular}{ll}
\hline \multicolumn{1}{c}{ Diretriz } & \multicolumn{1}{c}{ Descrição } \\
\hline 1. Escopo & $\begin{array}{l}\text { Emprego de simulação adequada do escoamento de ar no túnel e de dois modelos } \\
\text { reduzidos rígidos para simular o comportamento aerodinâmico }\end{array}$ \\
\hline $\begin{array}{l}\text { 2. Níveis de acurácia e de } \\
\text { precisão }\end{array}$ & $\begin{array}{l}\text { A complexidade da interação do vento com o silo, bem como as exigências à } \\
\text { preparação do modelo permitem adotar uma acurácia de } \pm 20 \% \text { e precisão de 20\% } \\
\text { aos resultados para a caracterização do vento, quando comparados aos valores de } \\
\text { referência dados pelas normas de vento. Em relação aos valores medidos de } \\
\text { pressão, a precisão é de 1\%. }\end{array}$ \\
\hline $\begin{array}{l}\text { 3. Exigências de } \\
\text { similaridade }\end{array}$ & $\begin{array}{l}\text { As condições de semelhança para a geometria, materiais e solicitações nos silos são } \\
\text { definidas pelo uso dos números adimensionais da Tabela 1. }\end{array}$ \\
\hline 4. Escolha dos materiais & $\begin{array}{l}\text { Os materiais são escolhidos para simular o comportamento da casca e das colunas } \\
\text { do modelo flexível e atender às semelhanças de rigidez, de aerodinâmica e de } \\
\text { geometria; na cobertura, para atender apenas às condições de geometria e de massa. }\end{array}$ \\
& $\begin{array}{l}\text { Para os modelos rígidos, o material não pode deformar-se e devem ser atendidas as } \\
\text { escalas geométrica e aerodinâmica. }\end{array}$ \\
\hline 5. Construção dos modelos & $\begin{array}{l}\text { Os modelos são confeccionados com o máximo de fidelidade aos protótipos. O } \\
\text { modelo flexível é fixado a uma base rígida e feito com colunas externas. Os } \\
\text { modelos rígidos são montados com superfícies lisa e nervurada. }\end{array}$ \\
\hline 6. Preparação e calibragem \\
do túnel
\end{tabular}

TABELA 5. Resumo das características dos ensaios.

\begin{tabular}{|c|c|c|c|c|c|c|c|c|c|}
\hline \multirow{2}{*}{\multicolumn{2}{|c|}{$\begin{array}{l}\text { Geometria dos } \\
\text { Modelos }\end{array}$}} & $\begin{array}{l}\text { Cilindro } \\
\text { H/D }\end{array}$ & $\begin{array}{l}\text { Cobe } \\
\text { inclir }\end{array}$ & $\begin{array}{l}\text { rtura } \\
\text { lação }\end{array}$ & \multicolumn{3}{|c|}{ Túnel de Camada Limite } & Terreno & $\begin{array}{c}\text { Condições dos Modelos no } \\
\text { Túnel }\end{array}$ \\
\hline & & $0,5-1,0$ & 26 , & $57^{\circ}$ & \multicolumn{3}{|c|}{ Circulação externa } & Campo & Modelos isolados \\
\hline \multicolumn{10}{|c|}{$\begin{array}{ll} & \text { Programa de Testes } \\
\end{array}$} \\
\hline \multicolumn{8}{|c|}{ Escalas (modelo/protótipo) ( chapas corrugadas*, colunas**) } & \multicolumn{2}{|r|}{ Medições } \\
\hline \multicolumn{3}{|c|}{ Geom $\quad$ Rigidez } & Massa & Tensão & Vel & Tempo & Reynolds & Pressões & Cotas de referência \\
\hline $1 / 42$ & $\begin{array}{c}\mathrm{E} \\
3 / 140^{*} \\
2 / 140^{*}\end{array}$ & $\begin{array}{c}\mathrm{I}, \mathrm{x} 10^{-6} \\
3,82^{*} \\
5,62^{* *}\end{array}$ & $1,26 \times 10^{-8}$ & $\begin{array}{l}2 / 7^{*} \\
1 / 3^{* *}\end{array}$ & $1 / 2$ & $1 / 21$ & $\begin{array}{l}7,36 \times 10^{5} \\
6,14 \times 10^{5}\end{array}$ & Médias & $\begin{array}{c}\mathrm{H} \text { - Cilindro } \\
\mathrm{H}+\mathrm{b}-\text { Cobertura }\end{array}$ \\
\hline
\end{tabular}

Tipos de Modelos

Aerodinâmico - H/D = 0,5 e 1,0

Aeroelástico $-\mathrm{H} / \mathrm{D}=1,0$

Em madeira, superfícies lisa e com nervuras.

Tomadas de pressão em linha. Modelo é girado

Casca em poliéster, nervuras em PET, similaridade nas escalas para medidas de pressão. aerodinâmica, de rigidez, e de massa; cobertura em madeira leve, escalas de geometria e de massa.

Tipos de Resultados

\begin{tabular}{|c|c|}
\hline $\begin{array}{l}\text { Modelos } \\
\text { rígidos }\end{array}$ & $\begin{array}{l}\text { Distribuições de pressões na superfície; } \\
\text { Coeficientes de arrasto no cilindro e de sustentação e de arrasto na cobertura, e } \\
\text { Visualização de escoamento com linhas de seda na superfície dos modelos . }\end{array}$ \\
\hline $\begin{array}{l}\text { Modelo } \\
\text { Aeroelástico }\end{array}$ & $\begin{array}{l}\text { Medições dos deslocamentos estáticos na coluna } 1 \mathrm{a} \mathrm{z}=0,5 \mathrm{H} \mathrm{e} \mathrm{z}=0,75 \mathrm{H}(\mathrm{z}=\text { altura); } \\
\text { Medições dos deslocamentos aeroelásticos do corpo cilíndrico, em } \mathrm{z}=\mathrm{H} / 2,-4,5^{\circ}<\theta<+4,5^{\circ} \\
\text { (colunas 1), por meio de imagens; } \\
\text { Medições dos tempos de deflexão da casca cilíndrica, e } \\
\text {.Configurações de deformações por meio de imagens do modelo. }\end{array}$ \\
\hline
\end{tabular}




\section{RESULTADOS E DISCUSSÃO}

A metodologia conduz à caracterização do escoamento de ar no túnel e das distribuições de pressão nos modelos de silos. Os dados obtidos no túnel consistem em respostas elétricas do anemômetro de fio quente em volts, convertidas para velocidade em $\mathrm{m} \mathrm{s}^{-1}$, e normalizadas em relação à velocidade média igual a $14,43 \mathrm{~m} \mathrm{~s}^{-1}$ a $238 \mathrm{~mm}$ de altura, respectivamente, $104 \mathrm{~km} \mathrm{~h}^{-1}$ e $10 \mathrm{~m} \mathrm{em}$ escala real - vide fatores de escala na Tabela 5. Os resultados são apresentados para a velocidade e a intensidade de turbulência calculadas comparativamente às normas ESDU 92032 (1995) e NBR 6123 (ABNT, 1990). Na Figura 5, são mostrados os perfis das velocidades normalizadas dos ensaios (1/42) e das normas brasileiras, NBR 6123 (ABNT, 1990), e inglesa ESDU 92032 (1995).
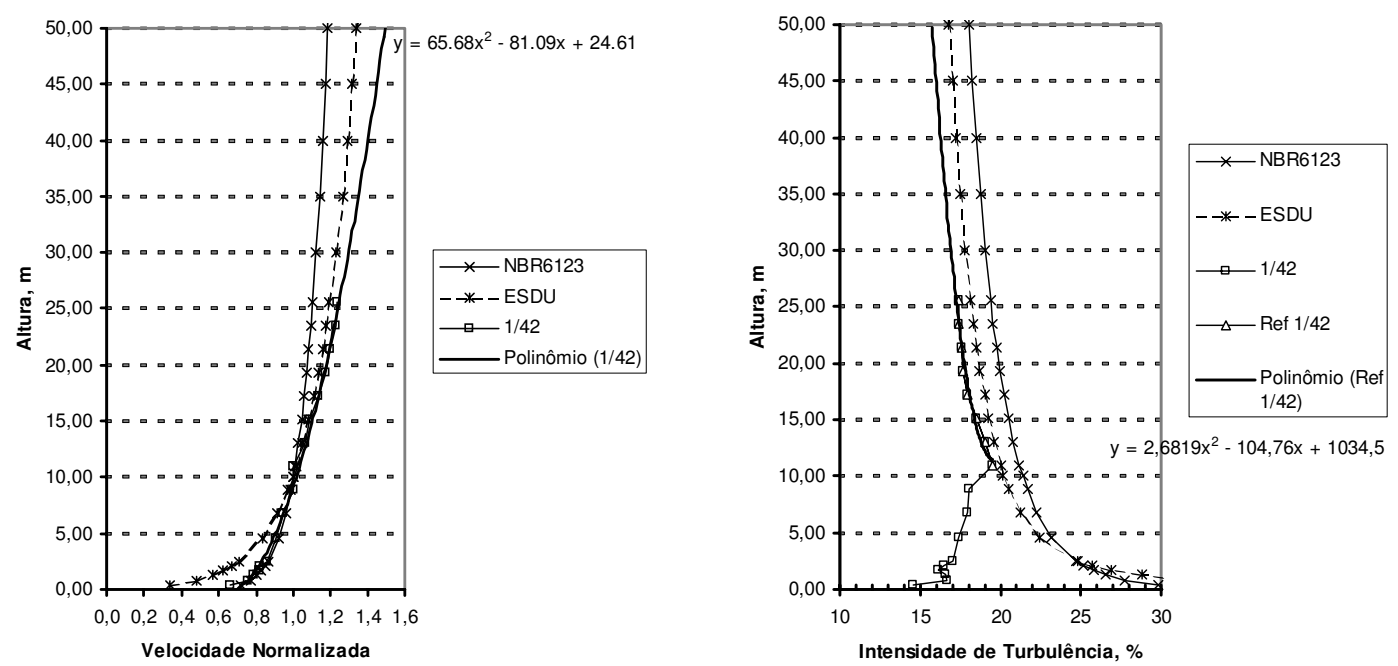

FIGURA 5. Perfis de velocidade e de intensidade normalizada, e linhas de tendência dos resultados.

As diferenças percentuais para as velocidades médias do vento no túnel são cerca de $4 \%$ maiores em relação às obtidas pela NBR 6123 (ABNT, 1990), na faixa de 1,0 m até $19,0 \mathrm{~m}$ de altura, e $10 \%$ maiores na faixa de 19,0 até $26,0 \mathrm{~m}$. Para a altura de referência igual a 10,0 m, o fator de velocidade é $\lambda_{\mathrm{U}}=1 / 1,82$, obtido pela divisão da velocidade $14,43 \mathrm{~m} \mathrm{~s}^{-1}$ no túnel e $26,25 \mathrm{~m} \mathrm{~s}^{-1}$ da NBR 6123 (ABNT, 1990). Para as intensidades de turbulência, há diferenças para menos em relação aos valores da NBR 6123, da ordem de $20 \%$ entre 5,0 e 9,0 m, e de $10 \%$ a partir de 10,0 m até os 25,6 m de altura. Vale lembrar que o modelo $\mathrm{H} / \mathrm{D}=0,5$ tem $518 \mathrm{~mm}$ de altura total $(21,76 \mathrm{~m}$ em escala real $)$, e o modelo 1,0 tem $638 \mathrm{~mm}(26,8 \mathrm{~m})$. Considerando-se que o nível de acurácia é igual a $30 \%$, os resultados atendem às exigências de simulação dos perfis de velocidade e de intensidade de turbulência.

As diferenças máximas nas velocidades são pequenas, da ordem de $10 \%$ e, desse modo, garantese a simulação correta das forças médias do vento. Em relação às intensidades de turbulência, somente abaixo de $5 \mathrm{~m}$ é que as diferenças são maiores que $20 \%$. As escalas de turbulência são obtidas da autocorrelação entre os componentes flutuantes em torno da velocidade média, para três faixas: 1) baixa, $U=3,94 \mathrm{~m} \mathrm{~s}^{-1}$; 2) média, $\mathrm{U}=11,40 \mathrm{~m} \mathrm{~s}^{-1}$, e 3) alta, $\mathrm{U}=15,56 \mathrm{~m} \mathrm{~s}^{-1}$. As velocidades de referência são medidas a $238 \mathrm{~mm}$ de altura. Na Figura 6, apresentam-se os gráficos para as escalas temporal e espacial da turbulência. 

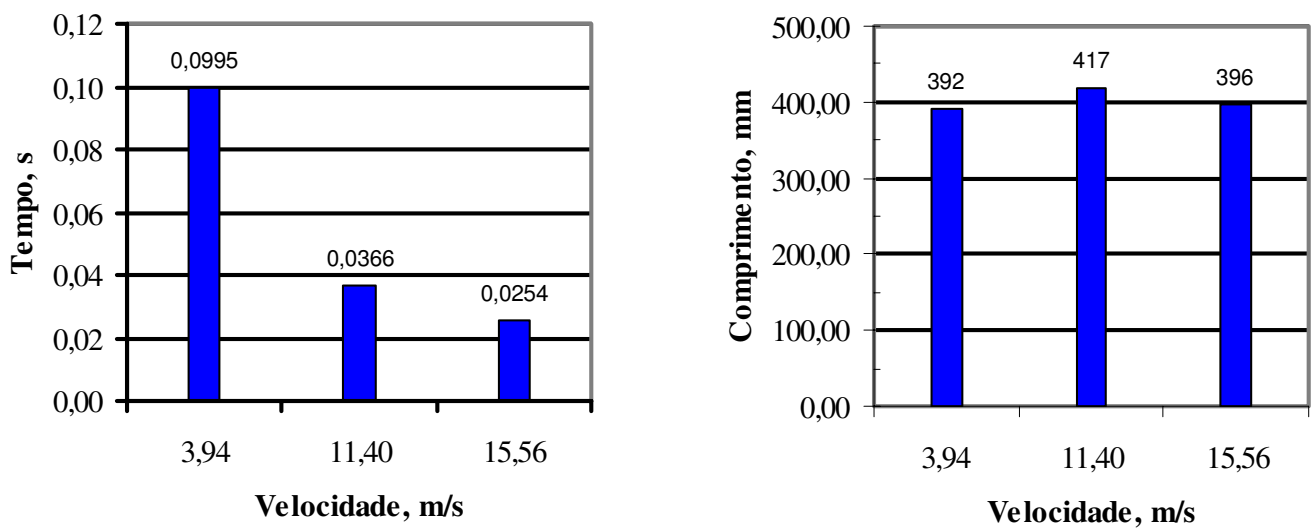

FIGURA 6. Escalas temporais e espaciais de turbulência.

As escalas espacial e temporal da turbulência são adequadas para a simulação da resposta do modelo flexível à ação do vento. A espacial porque garante turbilhões de tamanho médio suficiente (da ordem de $400 \mathrm{~mm}$ ) para excitar globalmente o modelo flexível. A temporal porque garante rajadas de duração média entre $0,025 \mathrm{~s} \mathrm{e} 0,1 \mathrm{~s}$, o suficiente para serem medidas as pressões médias em intervalos de 5 s. Outro parâmetro muito importante é dado pelo número de Reynolds que, para ambos os modelos rígidos, é maior que $1,0 \times 10^{5}$, o que garante a similaridade aerodinâmica entre os modelos e os silos reais. Isso significa que o escoamento médio (medido pela velocidade média) e os turbilhões (medidos pela intensidade de turbulência, que é o componente flutuante em torno da velocidade média) exercem forças no modelo semelhantes às forças do vento sobre os silos em escala natural.

As pressões nas superfícies externas dos silos em escala real podem ser determinadas a partir das distribuições dos coeficientes de pressão externa $\left(\mathrm{C}_{\mathrm{pe}}\right)$ nos modelos. Isso porque os coeficientes são adimensionais, com referência a uma pressão em uma dada altura. As alturas de referência são $\mathrm{H}$ (altura do cilindro) e $\mathrm{H}+\mathrm{b}$ (altura total do silo, dada pela altura do corpo mais a altura da cobertura) para velocidades $U_{\text {ref }}$, respectivamente, para as alturas de referência definidas. Portanto, os resultados obtidos para os modelos nos testes do túnel de vento são as distribuições dos coeficientes de pressões externas.

As pressões nos modelos foram obtidas por meio de manômetros digitais, controlados por válvulas automáticas de tomadas de pressão, com tempo de aquisição igual a $5 \mathrm{~s}$, em cada ponto da rede de tomadas de pressão (1.502 pontos no modelo com relação a altura e diâmetro H/D = 0,5 - ou simplesmente modelo 0,5 - e 1.388 pontos no modelo 1,0), isso para uma pausa depois de cada medição de $1 \mathrm{~s}$, e pausa antes do início da medição nas tomadas de $3 \mathrm{~s}$. É importante notar que o tempo de aquisição de $5 \mathrm{~s}$ é consideravelmente maior que o período da flutuação $(0,1 \mathrm{~s}$ máximo, conforme o gráfico da escala temporal da turbulência na Figura 6). Ou seja, os valores usados nos cálculos são representativos para a caracterização das linhas de corrente do escoamento turbulento.

Pelas distribuições de pressões obtidas nos ensaios, é possível determinar o que se altera no escoamento do ar sobre o silo devido às colunas ou montantes externos. A título de exemplo, nas Figuras 7 e 8 , são mostrados os coeficientes de pressão externa $\left(C_{\mathrm{pe}}\right)$ para o modelo 1,0. Para os silos de relação $\mathrm{H} / \mathrm{D}=0,5$, as reduções nos coeficientes de pressão externa, devido às colunas externas, são da ordem de $30 \%$ para o cilindro e $25 \%$ para a cobertura. Para o modelo 1,0 a redução chega a $40 \%$ no cilindro e $25 \%$ na cobertura. 

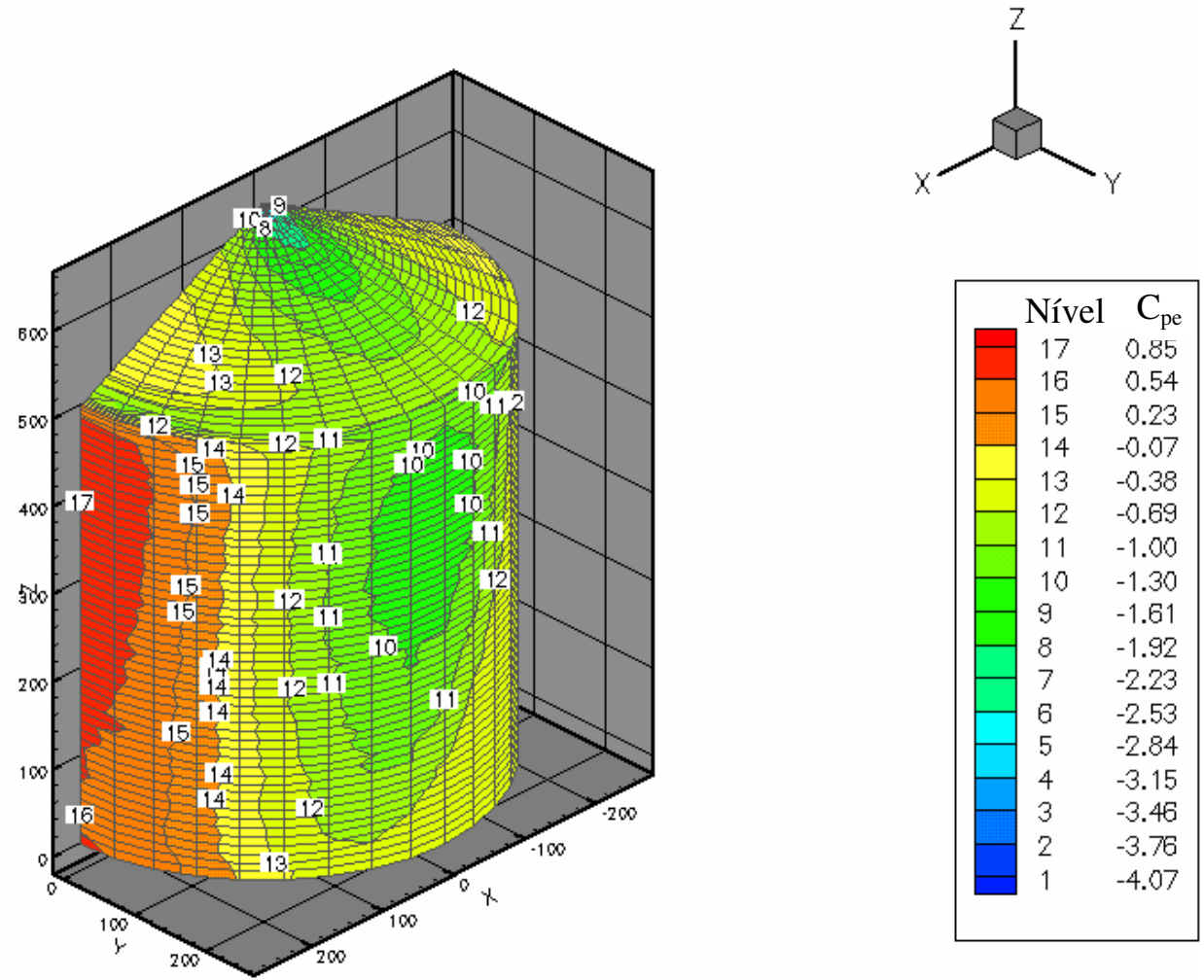

FIGURA 7. Coeficientes de pressão externa $\left(\mathrm{C}_{\mathrm{pe}}\right)$ para o modelo 1,0 em superfície lisa.
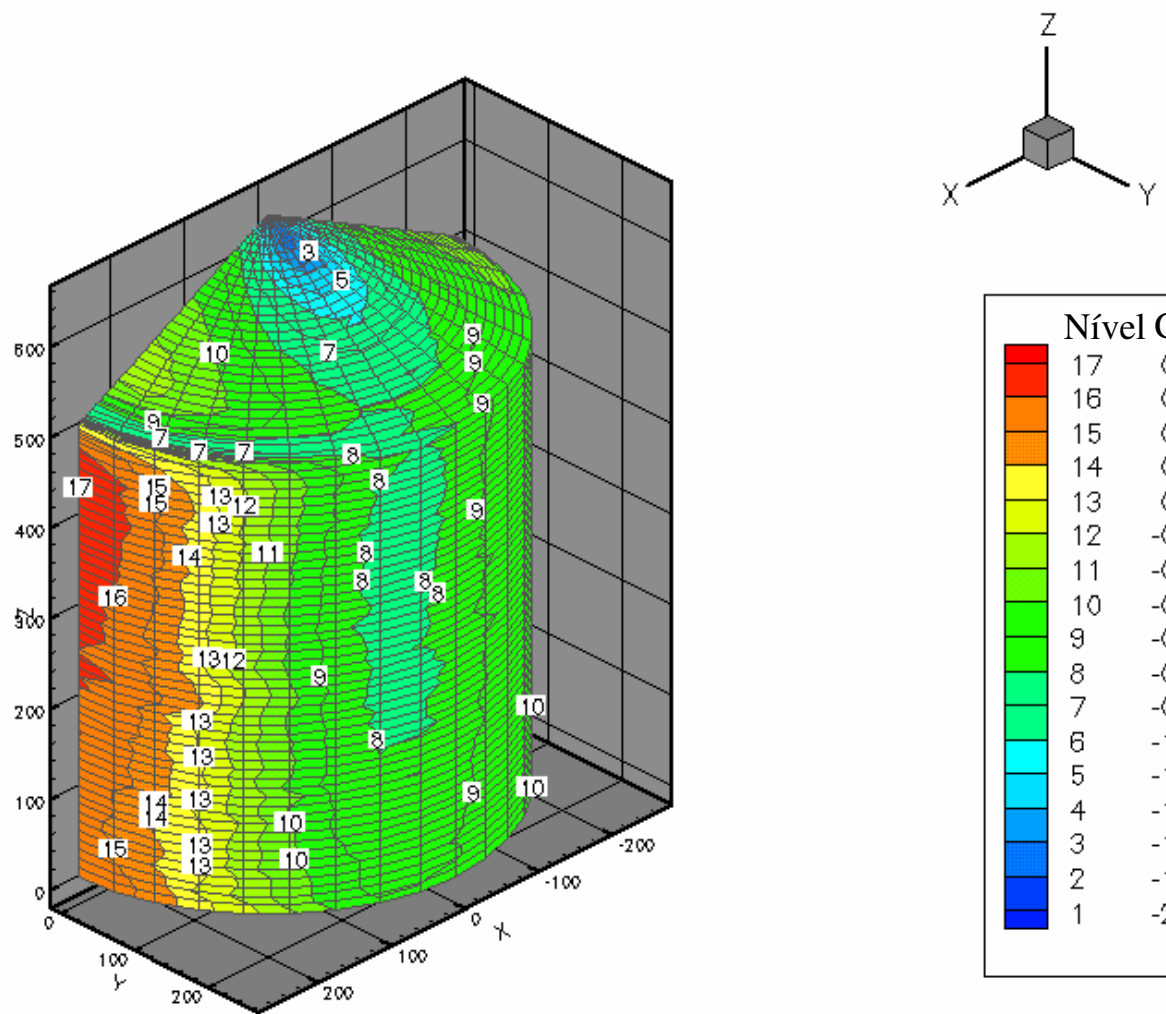

\begin{tabular}{|cc|}
\hline \multicolumn{3}{|c|}{ Nível $\mathrm{C}_{\mathrm{pe}}$} \\
17 & 0.87 \\
16 & 0.69 \\
15 & 0.51 \\
14 & 0.32 \\
13 & 0.14 \\
12 & -0.04 \\
11 & -0.22 \\
10 & -0.41 \\
9 & -0.59 \\
8 & -0.77 \\
7 & -0.95 \\
6 & -1.14 \\
5 & -1.32 \\
4 & -1.50 \\
3 & -1.68 \\
2 & -1.87 \\
1 & -2.05 \\
\hline & \\
\hline
\end{tabular}

FIGURA 8. Coeficientes de pressão externa $\left(\mathrm{C}_{\mathrm{pe}}\right)$ para o modelo 1,0 em superfície com elementos. 
Na Tabela 6, são apresentados os coeficientes aerodinâmicos sugeridos para a relação de altura das nervuras próximas a 0,01 D (a NBR 6123 não dispõe de valores para coberturas cônicas).

TABELA 6. Valores dos coeficientes de arrasto e de sustentação para as coberturas cônicas de inclinação $27^{\circ}(\mathrm{b} / \mathrm{D}=1 / 4)$ para silos com relação $\mathrm{H} / \mathrm{D}=0,5$ e 1,0 .

\begin{tabular}{ccrc}
\hline Superfície & H/D & $\mathrm{C}_{\mathrm{a}}$ & $\mathrm{C}_{\mathrm{s}}$ \\
\hline Lisa & \multirow{2}{*}{0,5} & $-0,02$ & $-0,55$ \\
Nervurada 0,01 D & & 0,03 & $-0,50$ \\
\hline Lisa & \multirow{2}{*}{1,0} & $-0,03$ & $-0,75$ \\
Nervurada 0,01 b & \multirow{2}{*}{$-0,02$} & $-0,65$ \\
\hline
\end{tabular}

Os valores dos coeficientes de arrasto $\mathrm{C}_{\mathrm{a}}$ sugeridos pela norma brasileira de Forças devidas ao vento em edificações, NBR 6123 (ABNT, 1990), são mantidos para os silos lisos. Para os cilindros com colunas externas de altura próxima a $0,01 \mathrm{D}$, é sugerido o valor 0,6 , inferior ao da NBR 6123, que adota 0,7 para a relação 0,02 D. Para relações próximas a 0,08 D, os valores da NBR 6123 são mantidos. Para relações intermediárias, os coeficientes podem ser estimados por interpolação linear.

Os resultados dos coeficientes aerodinâmicos propostos são mostrados na Tabela 7. Mantendo-se as mesmas condições da norma brasileira de ventos, NBR 6123, que é o número de Reynolds acima de $4,2 \times 10^{5}$, ou D.U $>6,14 \mathrm{~m}^{2} \mathrm{~s}^{-1}$, é proposta uma altura de referência em $\mathrm{H}$, porque se reporta diretamente à geometria do silo, e o valor da pressão dinâmica $q$ do vento é facilmente calculado para essa altura. Desse modo, são dados, na Tabela 8, os valores dos $\mathrm{C}_{\mathrm{pe}}$ para os cilindros de relação $\mathrm{H} / \mathrm{D}=0,5$ e 1,0. Para os cilindros com relação $\mathrm{H} / \mathrm{D}=0,5$, os valores dos $\mathrm{C}_{\mathrm{pe}}$ da norma brasileira podem ser usados para a superfície lisa e, se usados para a superfície com elementos externos, ou nervuras, os valores estão a favor da segurança. Para os cilindros com relação $H / D=1,0$, os $C_{\text {pe }}$ positivos obtidos no presente trabalho estão de acordo com aqueles fornecidos pela norma brasileira, mas são diferentes na região de pressões negativas, principalmente para o cilindro liso. Também foram detalhados os valores dos $\mathrm{C}_{\mathrm{pe}}$ na junção do corpo cilíndrico à cobertura cônica. $\mathrm{O}$ efeito é uma redução significativa, em torno de $60 \%$, devido à colocação dos fios, o que é benéfico à estrutura do silo.

TABELA 7. Valores dos coeficientes de arrasto para silos cilíndricos com relação $H / D=0,5$ e 1,0

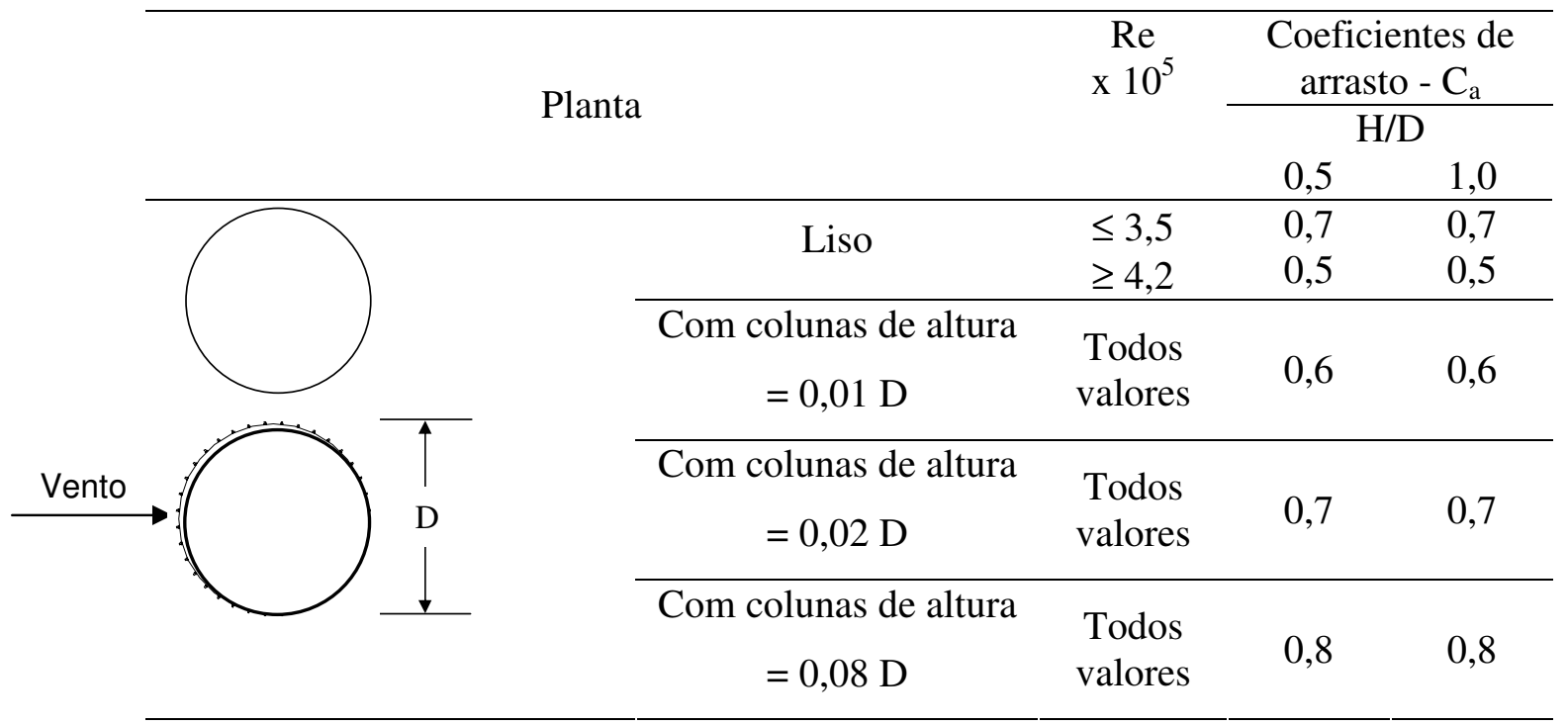


TABELA 8. Distribuição das pressões externas para os silos cilíndricos de relação H/D = 0,5 e 1,0.

\begin{tabular}{|c|c|c|c|c|c|}
\hline \multirow{3}{*}{$\theta$} & \multicolumn{4}{|c|}{ Coeficientes de pressão externa, $\mathrm{C}_{\mathrm{pe}}$} & \\
\hline & \multicolumn{2}{|c|}{ Superfície Lisa } & \multicolumn{2}{|c|}{ Superfície com Colunas } & \\
\hline & 0,5 & 1,0 & 0,5 & 1,0 & \\
\hline $0^{\circ}$ & 0,9 & 0,85 & 0,80 & 0,85 & $\mathrm{H}$ \\
\hline $10^{\circ}$ & 0,8 & 0,8 & 0,75 & 0,7 & \\
\hline $20^{\circ}$ & 0,6 & 0,5 & 0,6 & 0,5 & $\mathbb{Z Z}$ \\
\hline $30^{\circ}$ & 0,3 & 0,2 & 0,4 & 0,2 & 1 \\
\hline $35^{\circ}$ & 0,15 & 0 & 0 & 0 & \\
\hline $40^{\circ}$ & 0 & $-0,2$ & $-0,3$ & $-0,3$ & \\
\hline $50^{\circ}$ & $-0,4$ & $-0,6$ & $-0,5$ & $-0,65$ & Sobre \\
\hline $60^{\circ}$ & $-0,75$ & $-1,0$ & $-0,7$ & $-0,8$ & \\
\hline $70^{\circ}$ & $-1,00$ & $-1,3$ & $-0,8$ & $-0,9$ & Vento \\
\hline $80^{\circ}$ & $-1,14$ & $-1,5$ & $-0,6$ & $-0,7$ & \\
\hline $90^{\circ}$ & $-1,14$ & $-1,5$ & $-0,6$ & $-0,6$ & \\
\hline $100^{\circ}$ & $-0,95$ & $-1,3$ & $-0,5$ & $-0,5$ & $\mathrm{H} / \mathrm{D}<2,5$ \\
\hline $110^{\circ}$ & $-0,39$ & $-1,0$ & $-0,5$ & $-0,5$ & \\
\hline $120^{\circ}$ & $-0,39$ & $-0,6$ & $-0,45$ & $-0,5$ & \\
\hline $140^{\circ}$ & $-0,39$ & $-0,5$ & $-0,4$ & $-0,5$ & Pressão dinâmica q à altura $\mathrm{H}$ \\
\hline $160^{\circ}$ & $-0,39$ & $-0,5$ & $-0,4$ & $-0,5$ & Pressao dinamica q a altura $\mathrm{H}$ \\
\hline $180^{\circ}$ & $-0,39$ & $-0,5$ & $-0,4$ & $-0,5$ & \\
\hline
\end{tabular}

Os valores dos $\mathrm{C}_{\mathrm{pe}}$ foram comparados aos da literatura (SABRANSKY \& MELBOURNE, 1987; MACDONALD et al., 1988, para os cilindros com superfície lisa; FLACHSBART, 1932; ACKERET, 1934 e PRIS, 1960, para cilindros com superfície nervurada) e indicam boa conformidade em relação aos pontos de separação do escoamento do cilindro liso. Para a cobertura lisa, há poucos resultados na literatura, mas os existentes comprovam os valores e a distribuição dos $\mathrm{C}_{\mathrm{pe}}$ obtidos neste trabalho (SABRANSKY \& MELBOURNE, 1987). Não foram encontrados resultados na literatura para coberturas cônicas com fios na cobertura, que representam as das dobras das telhas. Os valores derivados dos $\mathrm{C}_{\mathrm{pe}}$, que são os coeficientes de arrasto e de sustentação, revelam que os da NBR 6123 (1990) são conservadores para os cilindros nervurados, mas estão em conformidade para os cilindros lisos. Para os modelos nervurados, não há muitos artigos, e os que foram encontrados não são recentes, com cerca de 40 e até 70 anos (BLESSMANN, 1983). Desse modo, a contribuição é um conjunto de dados atualizados, com características de semelhança e simulação bem definidas, com repetições dos testes e aplicabilidade direta para silos cilíndricos com coberturas cônicas.

\section{CONCLUSÕES}

A análise dos coeficientes de pressão revela um melhor comportamento do silo com as colunas externas, comparativamente ao silo com superfície lisa. $\mathrm{O}$ que ocorre é uma redução significativa, da ordem de $40 \%$ para o modelo com relação $\mathrm{H} / \mathrm{D}=1,0$ e de $30 \%$ para o modelo com relação $\mathrm{H} / \mathrm{D}=0,5$, das pressões negativas no cilindro, e de $25 \%$ na cobertura cônicas de ambos os modelos. Em termos práticos, isso significa que os silos cilíndricos têm um desempenho otimizado à ação do vento com o posicionamento externo das colunas. Por conseguinte, o silo está menos suscetível ao amassamento e ao efeito de ovalização, porque as pressões no entorno do cilindro são aliviadas. Os coeficientes de arrasto são mostrados em função da altura das colunas de enrijecimento do costado do silo. Desde que não tenham uma altura maior que $0,01 \mathrm{D}$, as colunas também propiciam um alívio da força de arrasto sobre o silo, obedecendo a um número de Reynolds $<3,5 \times 10^{5}$, ou para $\mathrm{D} U<5,11 \mathrm{~m}^{2} \mathrm{~s}^{-1}$, que é o produto entre o diâmetro do silo (D) e a velocidade média (U) à altura do topo do costado. 
Os valores sugeridos pela NBR 6123 (ABNT, 1990) para os coeficientes de pressão no corpo do silo cilíndrico devem ser usados para um escoamento de ar acima da região crítica, ou seja, para número de Reynolds acima de 4,2 x $10^{5}$, ou seja, para $\mathrm{D} U>6,14 \mathrm{~m}^{2} \mathrm{~s}^{-1}$, e com a pressão dinâmica $q$ calculada à altura de referência igual a 10,0 m. Mantendo-se essas mesmas condições da norma, é proposta uma altura de referência em $\mathrm{H}$, porque se reporta diretamente à geometria do silo, e o valor da pressão dinâmica do vento pode ser facilmente calculado para essa altura.

Para os cilindros com relação $\mathrm{H} / \mathrm{D}=0,5$, os valores dos $\mathrm{C}_{\mathrm{pe}}$ da norma brasileira podem ser usados para a superfície lisa, e, se usados para a superfície com elementos externos, ou saliências, os valores estão a favor da segurança. Para os cilindros com relação $\mathrm{H} / \mathrm{D}=1,0$, os $\mathrm{C}_{\mathrm{pe}}$ positivos obtidos no presente trabalho estão de acordo com aqueles fornecidos pela norma brasileira, mas são diferentes na região de pressões negativas, principalmente para o cilindro liso.

Os coeficientes aerodinâmicos de arrasto e de sustentação para as coberturas cônicas são uma contribuição para a norma brasileira de vento que, na versão atual, não dispõe desses valores. No próximo trabalho, será mostrado o comportamento aeroelástico do silo com colunas externas e fornecidas informações sobre o posicionamento de anéis de enrijecimento em silos.

\section{AGRADECIMENTOS}

Ao Conselho Nacional de Desenvolvimento Científico e Tecnológico - CNPq, pelo crédito e financiamento ao trabalho.

\section{REFERÊNCIAS}

ACKERET, J. Winddruck-Untersuchungen an einem Gasbehälter-Modell. Escher-Wyss Mitteilungen, Zurich, v.7, n.5, p.115-20, 1934.

AMERICAN SOCIETY OF CIVIL ENGINEERS. Manual of practice for wind tunnel studies of buildings and structures. Reston: Virginia, 1997. 177 p. (Aerospace Division)

ANDRADE JÚNIOR, L.J. A ação do vento em silos cilíndricos de baixa relação altura/diâmetro. 2002. 151 f. Tese (Doutorado em Engenharia de Estruturas) - Escola de Engenharia de São Carlos, Universidade de São Paulo, São Carlos, 2002.

ANDRADE JÚNIOR, L.J.; CALIL JÚNIOR, C.; CANEIRO, F.L.L.B. Análise dimensional de modelos de silos em túnel de vento. In.: JORNADAS SUL-AMERICANAS DE ENGENHARIA ESTRUTURAL, 29., 2000, Montevidéu. Anais... Montevidéu: Associação Sul-americana Engenharia Estrutural, 2000. 1 CD ROM.

ANDRADE JÚNIOR, L.J.; CALIL JÚNIOR, C. Análise de rigidez de silos metálicos sob a ação do vento. In: CONGRESSO BRASILEIRO DE ENGENHARIA AGRÍCOLA, 28., 1999, Pelotas. Anais... Pelotas: Sociedade Brasileira de Engenharia Agrícola, 1999. 1 CD ROM.

ASSOCIAÇÃO BRASILEIRA DE NORMAS TÉCNICAS. NBR 6123: Forças devidas ao vento em edificações. Rio de Janeiro, 1990. 84 p.

BLESSMANN, J. Aerodinâmica das construções. Porto Alegre: Editora da Universidade Federal do Rio Grande do Sul, 1983. 255 p.

BLESSMANN, J. O vento na engenharia estrutural. Porto Alegre: Editora da Universidade/UFRGS, 1995. $166 \mathrm{p}$.

ENGINEERING SCIENCE DATA UNIT. Computer program for wind speeds and turbulence properties: flat or hilly sites in terrain with roughness changes. London: ESDU International, 1995. 29 p. (Item, 92032) 
FLACHSBART, O. Winddruck auf Gasbehälter. Ergebnisse der Aerodynamischen Versuchanstalt zu Göttingen, Göttingen, v.4, n.4, p.134-8, 1932.

MACDONALD, P.A.; KWOK, K.C.S.; HOLMES, J.D. Wind loads on circular storage bins, silos and tanks: I. Point pressure measureaments on isolated structures. Journal of Wind Engineering and Industrial Aerodynamics, Amsterdam, v.31, n.1, p.165-87, 1988.

PRIS, M.R. Études eerodynamiques, 3-10. Annales de l'Institut Technique du Bâtiment et des Travaux Publics, Paris, n.155, 163, 164, 170, 181, 186, 202, 26, 240, 1960-67.

SABRANSKY, I.J.; MELBOURNE, W.H. Design pressure distribution on circular silos. Journal of Wind Engineering and Industrial Aerodynamics, Amsterdam, v.26, n.1, p.65-84, 1987. 